\title{
SYNTHESIS, CRYSTAL STRUCTURES AND PRELIMINARY ANTIBACTERIAL ACTIVITIES OF NICKEL(II) AND ZINC(II) COMPLEXES DERIVED FROM 2-BROMO-6-[(3-CYCLOHEXYLAMINOPROPYLIMINO) METHYL]PHENOL
}

\author{
WEI LI, ${ }^{1, *}$ YI DING,$^{2}$ XIAO-SHAN CHENG,$^{3}$ ZHONGLU YOU ${ }^{3}$ \\ ${ }^{1}$ Department of Hepatobiliary and Pancreatic Surgery, The Second Affiliated Hospital of Dalian Medical University, Dalian 116023, P. R. China \\ ${ }^{2}$ Department of Otorhinolaryngology, The Second Affiliated Hospital of Dalian Medical University, Dalian 116023, P. R. China \\ ${ }^{3}$ Department of Chemistry and Chemical Engineering, Liaoning Normal University, Dalian 116029, P. R. China
}

\begin{abstract}
Two centrosymmetric mononuclear nickel(II) and zinc(II) complexes, $\left[\mathrm{NiL}_{2}\right] \cdot 2 \mathrm{NO}_{3}(1)$ and $\left[\mathrm{ZnL}_{2}(\mathrm{dca})_{2}\right]$ (2), where $\mathrm{L}$ is the zwitterionic form of 2-bromo-6[(3-cyclohexylaminopropylimino)methyl]phenol, and dca is the dicyanamide anion, have been synthesized. The complexes have been characterized by physicochemical methods and single crystal X-ray determination. Complex (1) crystallizes in the monoclinic space group $P 2_{1} / n$ with unit cell dimensions $a=7.0091(7) \AA$, $b=11.137(1) \AA, c=23.997(2) \AA, \beta=97.390(3)^{\circ}, V=1857.7(3) \AA^{3}, Z=2, R_{1}=0.0617$, and $w R_{2}=0.1632$. Complex $(2)$ crystallizes in the triclinic space group $P-1$ with unit cell dimensions $a=8.762(1) \AA, b=10.386(1) \AA, c=10.687(2) \AA, \alpha=85.209(2)^{\circ}, \beta=83.931(2)^{\circ}, g=88.734(2)^{\circ}, V=963.6(2) \AA^{3}, Z=1, R=0.0374$, and $w R_{2}=0.0873$. The $\mathrm{Ni}$ atom in (1) is in a square planar geometry, and the $\mathrm{Zn}$ atom in (2) is in an octahedral geometry. The preliminary antibacterial activities of the complexes were assayed.
\end{abstract}

Keywords: Schiff base, nickel complex, zinc complex, crystal structure, biological property

\section{INTRODUCTION}

Schiff base complexes play an important role in the development of coordination chemistry related to catalysis and enzymatic reactions, magnetism and molecular architectures. ${ }^{1-3}$ Schiff bases derived from the condensation of salicylaldehyde with primary amines represent an important class of chelating ligands, the metal complexes of which have been widely studied. ${ }^{4-9}$ A detailed search of literature indicates that only two ruthenium complexes, ${ }^{10}$ three zinc complexes, ${ }^{11,12}$ and one titanium complex ${ }^{13}$ with the Schiff bases derived from 3-bromosalicylaldehyde have been reported so far. Moreover, no complexes have been reported with the Schiff base ligand 2-bromo-6-[(3cyclohexylaminopropylimino)methyl]phenol (L; Scheme 1). In this paper, two new mononuclear Schiff base nickel(II) and zinc(II) complexes, [ $\left.\mathrm{NiL}_{2}\right] \cdot 2 \mathrm{NO}_{3}$ (1) and $\left[\mathrm{ZnL}_{2}(\mathrm{dca})_{2}\right](2)$, where $\mathrm{L}$ is the zwitterionic form of 2-bromo-6-[(3cyclohexylaminopropylimino)methyl]phenol, and dca is dicyanamide anion, have been prepared and characterized. The preliminary antibacterial activities have been investigated.

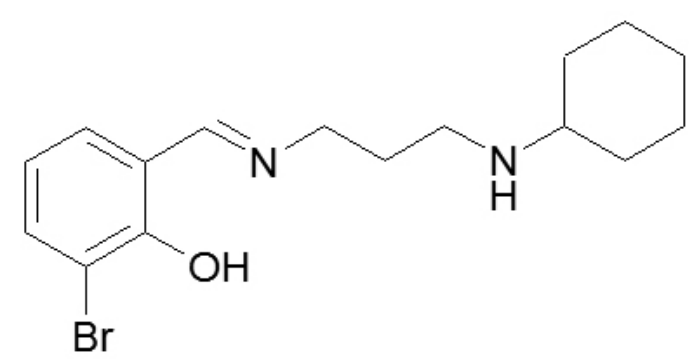

Scheme 1: The Schiff base L.

\section{EXPERIMENTAL}

Materials and Measurements: Commercially available 3-bromosalicylaldehyde and $N$-cyclohexylpropane-1,3-diamine were purchased from Lancaster and used without further purification. Other solvents and reagents were made in China and were used as obtained. $\mathrm{C}, \mathrm{H}$ and $\mathrm{N}$ elemental analyses were performed with a Perkin-Elmer 240C elemental analyser. IR spectra were recorded on a Nicolet AVATAR 360 spectrometer as $\mathrm{KBr}$ pellets in the $4000-400 \mathrm{~cm}^{-1}$ region.
Synthesis of L: The Schiff base ligand L was prepared by the condensation of 3-bromosalicylaldehyde $(1.0 \mathrm{mmol}, 201 \mathrm{mg})$ with $N$-cyclohexylpropane1,3-diamine (1.0 mmol, $156 \mathrm{mg})$ in methanol $\left(20 \mathrm{~cm}^{3}\right)$ at room temperature. Yield: $91 \%$. Anal. Calcd. for $\mathrm{C}_{16} \mathrm{H}_{23} \mathrm{BrN}_{2} \mathrm{O}$ (FW 339.3): C, 56.6; $\mathrm{H}, 6.8 ; \mathrm{N}, 8.3$. Found: $\mathrm{C}, 56.8 ; \mathrm{H}, 6.9 ; \mathrm{N}, 8.2 \%$.

Synthesis of Complex (1): To a methanol solution $\left(5 \mathrm{~cm}^{3}\right)$ of L $(0.1 \mathrm{mmol}$, $33.9 \mathrm{mg}$ ) was added a methanol solution $\left(5 \mathrm{~cm}^{3}\right)$ of nickel nitrate hexahydrate $(0.1 \mathrm{mmol}, 29.1 \mathrm{mg})$ with continuous stirring. The mixture was stirred for 20 min at room temperature to give a red solution. Upon keeping the solution in air for several days, red block-like single crystals suitable for X-ray diffraction were deposited at the bottom of the vessel. The isolated product was washed three times with cold methanol, and dried in a vacuum over anhydrous $\mathrm{CaCl}_{2}$. Anal. Calcd. for $\mathrm{C}_{32} \mathrm{H}_{3} \mathrm{Br}_{2} \mathrm{~N}_{6} \mathrm{NiO}_{8}$ (FW 861.3): C, 44.6; H, 5.4; N, 9.8. Found: C, $44.8 ; \mathrm{H}, 5.3 ; \mathrm{N}, 9.7 \%$. Yield, $12.5 \mathrm{mg}(29 \%$ on the basis of $\mathrm{L})$.

Synthesis of Complex (2): To a methanol solution $\left(5 \mathrm{~cm}^{3}\right)$ of $\mathrm{L}(0.1 \mathrm{mmol}$, $33.9 \mathrm{mg})$ was added a methanol solution $\left(5 \mathrm{~cm}^{3}\right)$ of zinc acetate dihydrate $(0.1$ $\mathrm{mmol}, 22.0 \mathrm{mg})$ and an aqueous solution of sodium dicyanamide $(0.1 \mathrm{mmol}$, $8.9 \mathrm{mg}$ ), with continuous stirring. The mixture was stirred for $20 \mathrm{~min}$ at room temperature to give a colorless solution. Upon keeping the solution in air for several days, colorless block-like single crystals suitable for X-ray diffraction were deposited at the bottom of the vessel. The isolated product was washed three times with cold methanol, and dried in a vacuum over anhydrous $\mathrm{CaCl}_{2}$. Anal. Calcd. for $\mathrm{C}_{36} \mathrm{H}_{46} \mathrm{Br}_{2} \mathrm{~N}_{10} \mathrm{O} Z \mathrm{Zn}$ ( $\mathrm{FW}$ 876.0): $\mathrm{C}, 49.4 ; \mathrm{H}, 5.3 ; \mathrm{N}, 16.0$. Found: C, 49.3; H, 5.3; N, 15.8\%. Yield, $21.3 \mathrm{mg}$ ( $49 \%$ on the basis of $\mathrm{L})$.

Crystal Structure Determination: Diffraction intensities for complexes (1) and (2) were collected at 298(2) K using a Bruker APEX II area-detector with $\mathrm{Cu} K a$ and $\mathrm{MoKa}$ radiation, respectively. The collected data were reduced using SAINT program, ${ }^{14}$ and multi-scan absorption corrections were performed using SADABS program. ${ }^{15}$ The structures were solved by direct methods and refined against $F^{2}$ by full-matrix least-squares methods using SHELXTL program. ${ }^{16}$ All of the non-hydrogen atoms were refined anisotropically. Hydrogen atoms in the complexes were placed in calculated positions and constrained to ride on their parent atoms. The crystallographic data for the complexes are summarized in Table 1. Selected bond lengths and angles are given in Table 2. Hydrogen bonding information is given in Table 3 . 
Table 1 Crystal data for (1) and (2).

\begin{tabular}{|c|c|c|}
\hline Complex & (1) & (2) \\
\hline Formula & $\mathrm{C}_{32} \mathrm{H}_{46} \mathrm{Br}_{2} \mathrm{~N}_{6} \mathrm{NiO}_{8}$ & $\mathrm{C}_{36} \mathrm{H}_{46} \mathrm{Br}_{2} \mathrm{~N}_{10} \mathrm{O}_{2} \mathrm{Zn}$ \\
\hline FW & 861.3 & 876.0 \\
\hline Crystal shape/colour & block/red & block/colorless \\
\hline Crystal size $/ \mathrm{mm}$ & $0.17^{\prime} 0.15^{\prime} 0.13$ & $0.20^{\prime} 0.20^{\prime} 0.17$ \\
\hline Crystal system & Monoclinic & Triclinic \\
\hline Space group & $P 2_{1} / n$ & $P-1$ \\
\hline$a / \AA$ & $7.009(1)$ & $8.762(1)$ \\
\hline$b / \AA$ & $11.137(1)$ & $10.386(1)$ \\
\hline$c / \AA$ & $23.997(2)$ & $10.687(2)$ \\
\hline$\alpha /{ }^{\circ}$ & & $85.209(2)$ \\
\hline$b /{ }^{\circ}$ & $97.390(3)$ & $83.931(2)$ \\
\hline$g /{ }^{\circ}$ & & $88.734(2)$ \\
\hline$V / \AA^{3}$ & $1857.7(3)$ & $963.6(2)$ \\
\hline$Z$ & 2 & 1 \\
\hline$l(\mathrm{MoKa}) / \AA$ & 0.71073 & 0.71073 \\
\hline$T / \mathrm{K}$ & $298(2)$ & $298(2)$ \\
\hline$m(\mathrm{MoKa}) / \mathrm{cm}^{-1}$ & 3.740 & 2.757 \\
\hline$T_{\min }$ & 0.5689 & 0.6086 \\
\hline$T_{\max }$ & 0.6420 & 0.6515 \\
\hline Reflections/parameters & $3632 / 223$ & $3585 / 232$ \\
\hline Restraints & 0 & 0 \\
\hline Goodness of fit on $F^{2}$ & 1.046 & 1.043 \\
\hline$R_{l}, w R_{2}\left[I^{3} 2 s(I)\right]^{\mathrm{a}}$ & $0.0617,0.1632$ & $0.0374,0.0873$ \\
\hline$R_{l}, w R_{2}(\text { all data })^{\mathrm{a}}$ & $0.0681,0.1704$ & $0.0635,0.0998$ \\
\hline
\end{tabular}

${ }^{\mathrm{a}} R_{l}=\mathrm{a}|| F O|-| F c|| / \mathrm{a}|| F O \mid, w R=\left[\mathrm{a} w\left(F O^{2}-F c^{2}\right)^{2} / \mathrm{a} w\left(F O^{2}\right)^{2}\right]^{1 / 2}, w_{(1)}=\left[\sigma^{2}(F O)^{2}\right.$ $\left.+\left(0.088\left(F o^{2}+2 F c^{2}\right) / 3\right)^{2}+2.3308\left(F o^{2}+2 F c^{2}\right) / 3\right]^{-1}, w_{(2)}=\left[\sigma^{2}(F o)^{2}+\left(0.0504\left(F O^{2}\right.\right.\right.$ $\left.\left.\left.+2 F c^{2}\right) / 3\right)^{2}+0.069\left(F o^{2}+2 F c^{2}\right) / 3\right]^{-1}$.

Table 2 Selected bond lengths $(\AA)$ and bond angles $\left({ }^{\circ}\right)$ for $(1)$ and $(2)^{\mathrm{b}}$

\begin{tabular}{|c|c|c|c|}
\hline$(1)$ & & & \\
\hline Ni1-O1 & $1.844(2)$ & Ni1-N1 & $1.934(3)$ \\
\hline O1-Ni1-O1A & 180 & O1-Ni1-N1 & $92.27(11)$ \\
\hline O1-Ni1-N1A & $87.73(11)$ & N1-Ni1-N1A & 180 \\
\hline$(2)$ & & & \\
\hline Zn1-O1 & $2.096(2)$ & Zn1-N1 & $2.118(2)$ \\
\hline Zn1-N3 & $2.203(3)$ & & \\
\hline O1-Zn1-O1B & 180 & O1-Zn1-N1 & $86.46(9)$ \\
\hline O1-Zn1-N1B & $93.54(9)$ & N1-Zn1-N1B & 180 \\
\hline O1-Zn1-N3B & $93.75(9)$ & N1-Zn1-N3B & $88.44(10)$ \\
\hline O1-Zn1-N3 & $86.25(9)$ & N1-Zn1-N3 & $91.56(10)$ \\
\hline N3-Zn1-N3B & 180 & & \\
\hline
\end{tabular}

${ }^{\mathrm{b}}$ Symmetry codes: $\mathrm{A}, 1-x,-y, 2-z ; \mathrm{B}, 1-x,-y, 1-z$.
Table 3 Geometrical parameters for hydrogen bonds.

\begin{tabular}{|c|c|c|c|c|}
\hline$D-\mathrm{H} \cdots A$ & $D-\mathrm{H}(\AA \hat{)})$ & $\mathrm{H} \cdots A(\AA \dot{)})$ & $\begin{array}{c}D \cdots A \\
(\AA)\end{array}$ & $\begin{array}{c}D-\mathrm{H} \cdots A \\
\left({ }^{\circ}\right)\end{array}$ \\
\hline \multicolumn{5}{|c|}{ (1) } \\
\hline $\mathrm{N} 2-\mathrm{H} 2 \mathrm{~B} \cdots \mathrm{N} 3^{\mathrm{i}}$ & 0.90 & 2.61 & $3.496(5)$ & 169 \\
\hline $\mathrm{N} 2-\mathrm{H} 2 \mathrm{~B} \cdots \mathrm{O} 3^{\mathrm{i}}$ & 0.90 & 2.46 & $3.254(6)$ & 148 \\
\hline $\mathrm{N} 2-\mathrm{H} 2 \mathrm{~B} \cdots \mathrm{O} 4^{\mathrm{i}}$ & 0.90 & 2.05 & $2.884(5)$ & 153 \\
\hline $\mathrm{N} 2-\mathrm{H} 2 \mathrm{~A} \cdots \mathrm{O} 3^{\mathrm{ii}}$ & 0.90 & 2.68 & $3.409(6)$ & 138 \\
\hline $\mathrm{N} 2-\mathrm{H} 2 \mathrm{~A} \cdots \mathrm{O} 2^{\mathrm{ii}}$ & 0.90 & 1.97 & $2.865(4)$ & 166 \\
\hline \multicolumn{5}{|c|}{ (2) } \\
\hline $\mathrm{N} 2-\mathrm{H} 2 \mathrm{~A} \cdots \mathrm{N} 4^{\mathrm{iii}}$ & 0.90 & 2.04 & $2.877(4)$ & 155 \\
\hline
\end{tabular}

Symmetry transformation used to generate the symmetry related atoms: (i) $2-x,-1-y, 2-z$; (ii) $x,-1+y, z$; (iii) $x, y,-1+z$.

\section{RESULTS AND DISCUSSION}

Preparation of the Complexes: Facile condensation of 3-bromosalicylaldehyde with $N$-cyclohexylpropane-1,3-diamine in a 1:1 molar ratio furnished the ligand $\mathrm{L}$ (Scheme 1). The nickel and copper complexes were formed in methanol solutions containing equimolar quantities of metal salts, L, and sodium dicyanamide (for (2)). The crystals of the complexes are soluble in most polar organic solvents such as methanol, ethanol, DMF, and DMSO. Elemental analyses are in good agreement with the chemical formulae proposed for the compounds. In dry methanol complex $\mathbf{1}$ behaves as a 1:2 electrolyte and complex 2 behaves as a non-electrolyte as reflected in their $\Lambda_{\mathrm{M}}$ values $\left(237 \Omega^{-1} \mathrm{~cm}^{2} \mathrm{~mol}^{-1}\right.$ for (1) and $25 \Omega^{-1} \mathrm{~cm}^{2} \mathrm{~mol}^{-1}$ for (2)). ${ }^{17}$ Melting points show that complexes (1) and (2) are stable up to $227^{\circ} \mathrm{C}$ and $165^{\circ} \mathrm{C}$, respectively.<smiles>Cc1ccc(/C=N/CCCNC2CCCCC2)c(O)c1Br</smiles>

L

Scheme 1. Synthesis procedure of L.

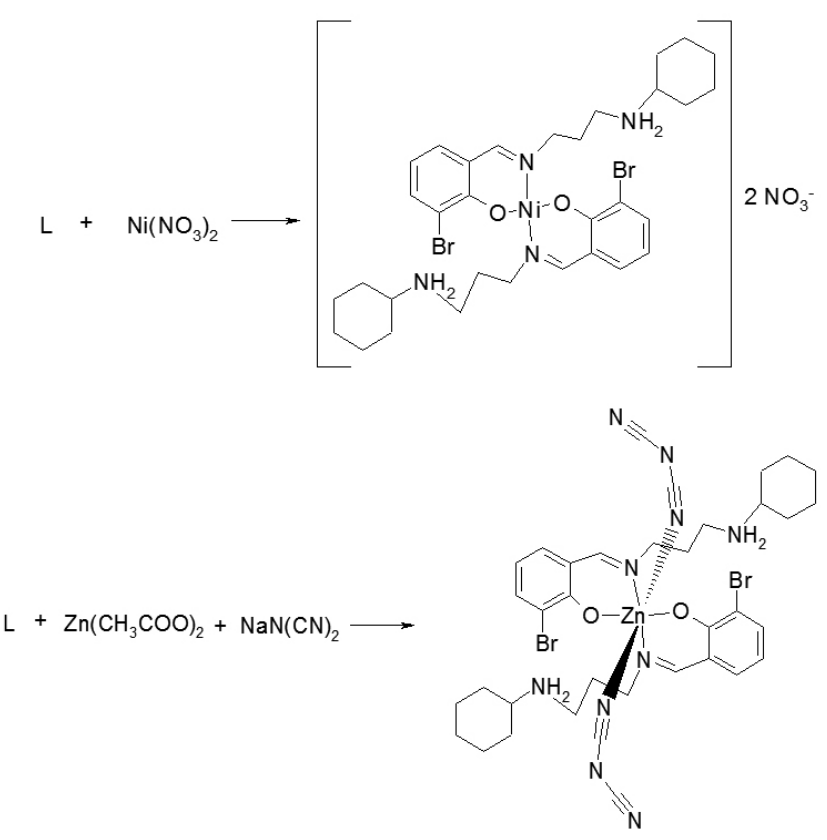

Scheme 2. Synthesis procedure of the complexes. 
Structure Description of Complex (1): Figure 1 gives perspective view of complex (1) together with the atomic labeling system. The complex contains a centrosymmetric mononuclear nickel(II) complex cation and two nitrate anions. The $\mathrm{Ni}$ atom, lying on the inversion center, is coordinated by two phenolate oxygen and two imino nitrogen from two zwitterionic Schiff base ligands, forming a square planar geometry. The observed crystal structure confirms the chair conformation of the associated cyclohexyl ring in the ligand. The Schiff base ligands bind to Ni atom in bidentate fashion, forming sixmembered chelate rings. The amino nitrogen is protonated, which participate in the formation of hydrogen bonds. The Ni-O and Ni-N bond lengths are comparable to those observed in similar nickel(II) complexes with Schiff bases. ${ }^{18,19}$

In the crystal structure of the complex, the nickel complex cations and the nitrate anions are linked through intermolecular $\mathrm{N}-\mathrm{H} \cdots \mathrm{N}$ and $\mathrm{N}-\mathrm{H} \cdots \mathrm{O}$ hydrogen bonds, to form 2D sheet (Figure 2)

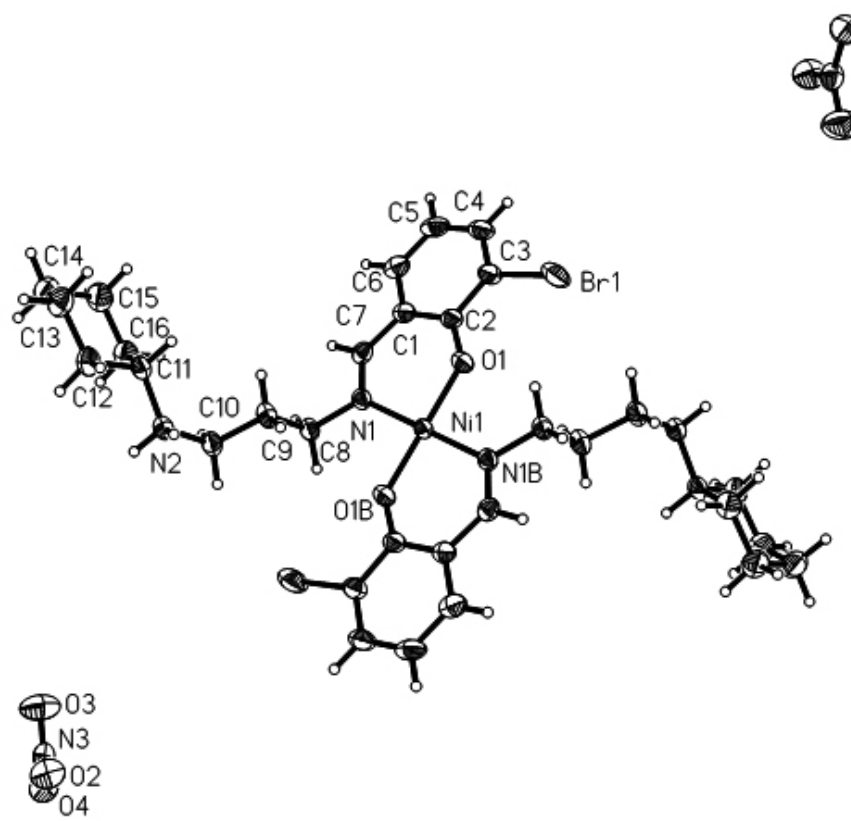

Figure 1 The structure of complex (1), showing the atom-numbering scheme. Displacement ellipsoids are drawn at the $30 \%$ probability level and $\mathrm{H}$ atoms are shown as small spheres of arbitrary radii.

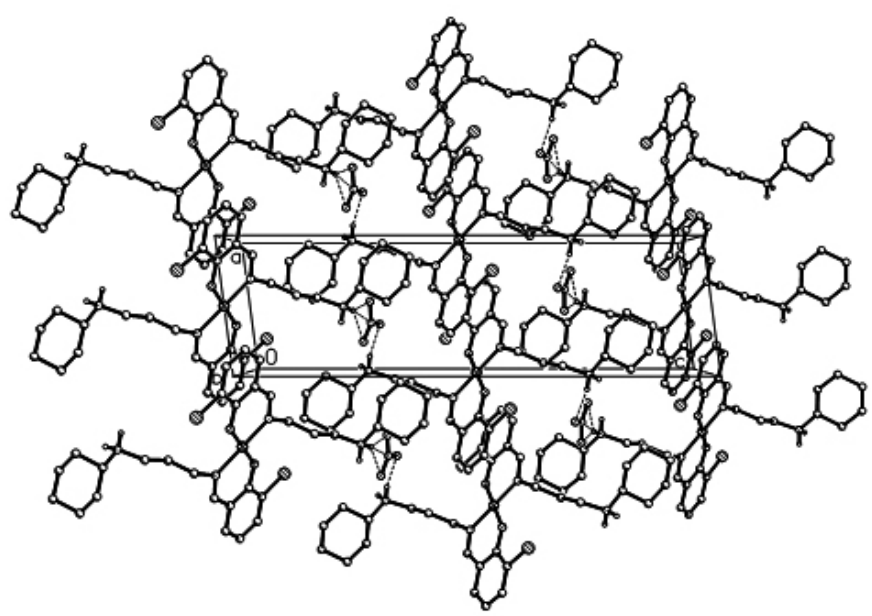

Figure 2 Molecular packing of complex (1), viewed along the $c$ axis. Hydrogen bonds are shown as dashed lines.
Structure Description of Complex (2): Figure 3 gives perspective view of complex (2) together with the atomic labeling system. The complex is a centrosymmetric mononuclear zinc compound, with the inversion center located at the $\mathrm{Zn}$ atom. The $\mathrm{Zn}$ atom is six-coordinated in an octahedral geometry. Four atoms O1, O1B, N1, and N1B from the bidentate zwitterionic Schiff base ligands occupy the meridian plane, while the axial positions are taken up by two nitrogen atoms, $\mathrm{N} 3$ and $\mathrm{N} 3 \mathrm{~B}$, coming from the coordinated dicyanamide ligands. The observed crystal structure confirms the chair conformation of the associated cyclohexyl ring in the ligand. The amino nitrogen is protonated, which participate in the formation of hydrogen bonds. In the octahedral coordination, $\mathrm{Zn}-\mathrm{O}$ and $\mathrm{Zn}-\mathrm{N}$ distances are comparable to those observed in other zinc(II) complexes with Schiff bases. ${ }^{20}$

In the crystal structure of the complex, the zinc complex molecules are linked through intermolecular $\mathrm{N}-\mathrm{H} \cdots \mathrm{N}$ hydrogen bonds, to form 1D chains running along the $c$ axis (Figure 4).

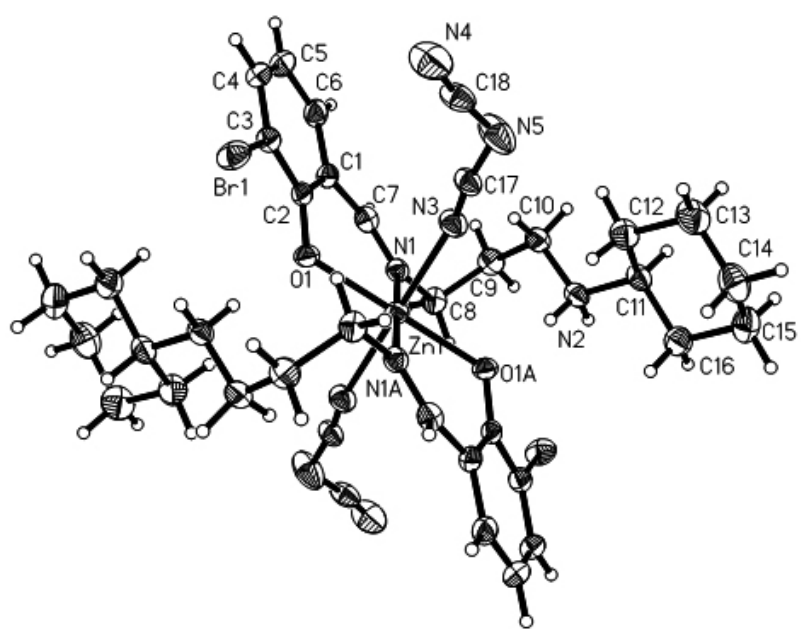

Figure 3 The structure of complex (2), showing the atom-numbering scheme. Displacement ellipsoids are drawn at the $30 \%$ probability level and $\mathrm{H}$ atoms are shown as small spheres of arbitrary radii.

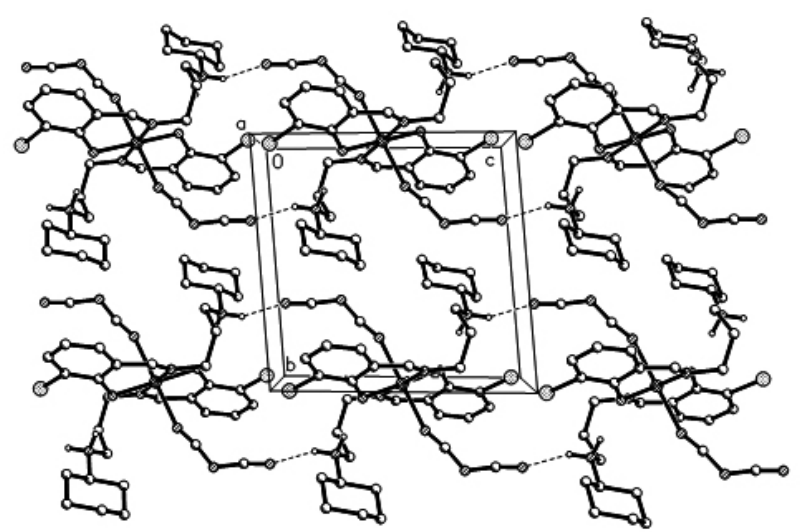

Figure 4 Molecular packing of complex (2), viewed along the $c$ axis. Hydrogen bonds are shown as dashed lines.

IR Spectra: In the IR spectra of the complexes, the strong bands due to the azomethine groups $(\mathrm{C}=\mathrm{N})$ are observed at $1621 \mathrm{~cm}^{-1}$ for $(1)$ and 1627 $\mathrm{cm}^{-1}$ for (2). IR spectrum of (1) also shows a band at $1390 \mathrm{~cm}^{-1}$ due to ionic nitrate. ${ }^{21}$ The IR spectrum of (2) exhibits three bands: $v(\mathrm{C} \equiv \mathrm{N})+v(\mathrm{C} \equiv \mathrm{N})$ at $2289 \mathrm{~cm}^{-1}, v_{\mathrm{sc}}(\mathrm{C} \equiv \mathrm{N})$ at $2237 \mathrm{~cm}^{-1}$ and $v_{\mathrm{s}}(\mathrm{C} \equiv \mathrm{N})$ at $2172 \mathrm{~cm}^{-1}$. These bands are as expected for terminal dicyanamide coordination. ${ }^{22}$ New bands in the IR spectra of complexes are in the range $400-600 \mathrm{~cm}^{-1}$ assigned to $v(\mathrm{M}-\mathrm{N})$ and $v(\mathrm{M}-\mathrm{O})$ stretching vibrations, ${ }^{23}$ confirming coordination of the ligand to metal through NO donors. 
Antibacterial Screening: The antibacterial assay was performed according to the literature method. ${ }^{27}$ Penicillin $\mathrm{G}$ was used as a standard drug. The zone of inhibition for the $5000 \mu \mathrm{g} \mathrm{mL}^{-3}$ test solutions (DMSO as the solvent) on the four bacteria, Escherichia coli, Pseudomonas aeruginosa, Salmonella typhi and Staphylococcus aureus is given in Table 4. The MIC values are given in Table 5 . The results indicated that there was from weak to negative activity observed by $\mathrm{L}$ against $P$. aeruginosa and $S$. aureus, and medium activity against $E$. coli and $B$. subtilis. It is noteworthy that the zones of inhibition areas are somewhat larger for the complexes than the ligand. The trend in this work is accord with those reported earlier, ${ }^{28,29}$ which have shown that metal complexes are more potent bactericidal than that of the corresponding Schiff bases. Among the compounds, complex (1) has most potent activity against $B$. subtilis with MIC value of $3.13 \mu \mathrm{g} \mathrm{mL}^{-3}$, which is even comparable to that of Penicillin G.

Table 4 Antibacterial screening results.

\begin{tabular}{|c|c|c|c|c|}
\hline \multirow{2}{*}{ Compound } & \multicolumn{4}{|c|}{ Zone of inhibition (mm) } \\
\cline { 2 - 5 } & E. coli & P. aeruginosa & B. subtilis & S. aureus \\
\hline L & $11 \pm 3.3$ & $6 \pm 3.3$ & $12 \pm 3.3$ & $-^{c}$ \\
\hline$(1)$ & $17 \pm 3.3$ & $15 \pm 5.8$ & $17 \pm 3.3$ & $13 \pm 3.3$ \\
\hline$(2)$ & $22 \pm 5.8$ & $25 \pm 3.3$ & $16 \pm 3.3$ & $18 \pm 3.3$ \\
\hline Penicillin G & $31 \pm 3.3$ & $27 \pm 3.3$ & $29 \pm 5.8$ & $25 \pm 3.3$ \\
\hline DMSO & - & - & - & - \\
\hline
\end{tabular}

c "_" indicates that the bacteria are resistant to the compound.

Table 5 Antibacterial activities as MIC values $\left(\mu \mathrm{g} \mathrm{mL}^{-3}\right)$.

\begin{tabular}{|c|c|c|c|c|}
\hline Compound & E. coli & P. aeruginosa & B. subtilis & S. aureus \\
\hline L & 50 & $>100$ & 50 & $>100$ \\
\hline$(1)$ & 12.5 & 25 & 3.13 & 12.5 \\
\hline$(2)$ & 6.25 & 25 & 6.25 & 25 \\
\hline Penicillin G & 3.13 & 6.25 & 1.56 & 6.25 \\
\hline
\end{tabular}

\section{SUMMARY}

Two new mononuclear nickel(II) and zinc(II) complexes with the zwitterionic ligand 2-bromo-6-[(3-cyclohexylammoniopropylimino)methyl] phenolate have been prepared and characterized. The complexes have from medium to effective antibacterial activities, which are interesting and deserve deeply study.

\section{SUPPLEMENTARY MATERIAL}

CCDC-945680 (1) and 945681 (2) contain the supplementary crystallographic data for this paper. The data can be obtained free of charge at http://www.ccdc.cam.ac.uk/const/retrieving.html or from the Cambridge Crystallographic Data Centre (CCDC), 12 Union Road, Cambridge CB2 1EZ, UK; fax: +44(0)1223-336033 or e-mail: deposit@ccdc.cam.ac.uk.

\section{REFERENCES}

1. N. Domracheva, A. Pyataev, R. Manapov, M. Gruzdev, U. Chervonova, A. Kolker, Eur. J. Inorg. Chem., 8, 1219, (2011).

2. N. Sathya, G. Raja, C. Jayabalakrishnan, Synth. React. Inorg. Met.-Org. Nano-Met. Chem., 41, 81, (2011).

3. Y. He, C. Cai, Catal. Commun., 12, 678, (2011).

4. W.-X. Feng, Y.-N. Hui, T. Wei, X.-Q. Lu, J.-R. Song, Z.-N. Chen, S.-S. Zhao, W.-K. Wong, R.A. Jones, Inorg. Chem. Commun., 14, 75, (2011).

5. I. Correia, S. Marcao, K. Koci, I. Tomaz, P. Adao, T. Kiss, T. Jakusch, F. Avecilla, J.C. Pessoa, Eur. J. Inorg. Chem., 5, 694, (2011).

6. J.-C. Zhang, X.-S. Zhou, X.-L. Wang, X.-F. Li, Z.-L. You, Transition Met. Chem., 36, 93, (2011).

7. L.-W. Xue, X.-W. Li, G.-Q. Zhao, W.-C. Yang, Russ. J. Coord. Chem., 39, 872, (2013).

8. Y. Xiong, Synth. React. Inorg. Met.-Org. Nano-Met. Chem., 43, 961, (2013).

9. Q.-W. Yang, Y. Lei, P. Wang, Synth. React. Inorg. Met.-Org. Nano-Met. Chem., 44, 1208, (2014)

10. G.-Y. Li, J. Zhang, P.W.H. Chan, Z.-J. Xu, N.Y. Zhu, C.-M. Che, Organometallics, 25, 1676, (2006).
11. E.C. Escudero-Adan, M.M. Belmonte, E. Martin, G. Salassa, J. BenetBuchholz, A.W. Kleij, J. Org. Chem., 76, 5404, (2011).

12. C.-L. Han, Acta Crystallogr., E68, m677, (2012).

13. A. Tzubery, E.Y. Tshuva, Inorg. Chem., 51, 1796, (2012).

14. SMART and SAINT, Area Detector Control and Integration Software, Madison (WI, USA): Bruker Analytical X-ray Instruments Inc., (1997).

15. G.M. Sheldrick, SADABS, Program for Empirical Absorption Correction of Area Detector Data. Göttingen (Germany): University of Göttingen, (1997).

16. G.M. Sheldrick, SHELXL-97, Program for the Refinement of Crystal Structures, Göttingen (Germany): University of Göttingen, (1997).

17. W.J. Geary, Coord. Chem. Rev., 7, 81, (1971).

18. S. Mukhopadhyay, D. Mandal, D. Ghosh, I. Goldberg, M. Chaudhury, Inorg. Chem., 42, 8439, (2003).

19. P. Mukherjee, M.G.B. Drew, A. Ghosh, Eur. J. Inorg. Chem., 3372, (2008).

20. S. Basak, S. Sen, S. Mitra, G. Rosair, M.T.G. Rodriguez, Polyhedron, 26, 5104, (2007).

21. S. Chandra, A.K. Sharma. Spectrochim. Acta A, 72, 851, (2009).

22. F.A. Mautner, J.B. Soileau, P.K. Bankole, A.A. Gallo, S.S. Massoud, J. Mol. Struct. 889, 271, (2008).

23. J.R. Ferraro, Low Frequency Vibrations of Inorganic and Coordination Compounds, Plenum Press, New York, (1971).

24. H.-J. Zhang, X. Qin, K. Liu, D.-D. Zhu, X.-M. Wang, H.-L. Zhu, Bioorg. Med. Chem., 19, 5708, (2011).

25. W. Li, B.-W. Ding, H. Sun, X.-L. Wang, Z. You, Synth. React. Inorg. Met.-Org. Nano-Met. Chem., 42, 666, (2012).

26. T. Rosu, M. Negoiu, S. Pasculescu, E. Pahontu, D. Poirier, A. Gulea, Eur. J. Med. Chem., 45, 774, (2010). 